Brit. J. vener. Dis. (1957), 33, 179.

\title{
STREPTOMYCIN-RESISTANT GONORRHOEA IN THE FEMALE
}

\author{
BY \\ A. C. C. DAVEY \\ Assistant Venereologist, Royal Infirmary, Manchester
}

There were 17,845 infections of gonorrhoea reported in 1955 by the V.D. clinics of England and Wales. How many other cases were treated and not reported is unknown. Several reasons have been advanced to explain why gonorrhoea should still be so prevalent after 10 years of penicillin therapy in spite of the known effectiveness of this antibiotic. The chief reason is surely the difficulty of eradicating the disease from those of the promiscuous section of the female population in whom symptoms are so slight, or who themselves are so ignorant, that they do not seek treatment until they have developed one of the late complications of gonorrhoea. However, there is a further possibility why some of these women may become gonococcal carriers, namely, their treatment with streptomycin. This drug is still used in cases of acute gonorrhoea, either as a routine to avoid the hypothetical risk of masking early syphilis by the administration of penicillin, or where the patient is known to be sensitive to penicillin. In the male, as in the case reported by Ryan (1952), failure to cure with streptomycin is relatively unimportant, because the patient, aware of his persisting symptoms, returns for further therapy. In the female, however, the position is very different, for she may never have had definite symptoms and, having received her injections, she defaults under the impression that she is cured. Thus a further gonococcal carrier is added to the small but sexually active group of females which is to be found in the larger cities. The following case which illustrates this point may therefore be of interest.

\section{Case History}

History.-An unmarried, white female, aged 22 years attended the clinic on April 13, 1956, stating that her consort, with whom she had been living for some time, had developed an urethral discharge. On questioning, she admitted to a vaginal discharge and some dysuria of 3 days' duration accompanied by some lower abdominal pain. She had been treated for gonorrhoea with

\footnotetext{
* Received for publication May 30, 1957
}

penicillin 1 year previously at St. Luke's Clinic, Manchester.

Examination.-There was an urethritis, cervical infection, and tenderness over the left Fallopian tube. Smears from the urethra and cervix were positive for gonococci. Trichomonas vaginalis was also found. The blood Wassermann reaction and Kahn test were reported to be negative.

Treatment.-Streptomycin, prescribed for another case who was known to be sensitive to penicillin, was given in error to the patient reported here. She received $1 \mathrm{~g}$. streptomycin on April 13, 14, and 15, and was instructed to use two Stovarsol vaginal compound (S.V.C.) pessaries at night for the $T$. vaginalis infection.

Follow-up.-On April 20, i.e. 4 days after her last streptomycin injection, she was re-examined and found to have a profuse vaginal discharge and a purulent cervical infection. A smear and a culture of the cervical discharge were both positive for gonotocci. Clinically the picture was unchanged from the previous week and the patient indignantly denied further coitus. The gonococci were sub-cultured and proved resistant to streptomycin in vitro $(30 \mathrm{mg}$.). The patient was then given 600,000 units procaine penicillin after vaginal toilet with Aminocrine and Cetavlon and the insertion of three tablets of S.V.C. She returned 7 days later but examination was postponed for 3 days as she was menstruating. Unfortunately she defaulted and it has proved impossible to locate her.

\section{Comment}

The default of this patient emphasizes the possible danger of treating gonorrhoea in the female with streptomycin unless adequate surveillance can be insured.

\section{Summary}

A case of streptomycin-resistant gonorrhoea in a female is described. The danger of so producing a gonococcal carrier is stressed.

\section{REFERENCE}

Ryan, W. J. (1952). British Journal of Venereal Diseases, 28, 209. 